\title{
XRD and TEM analysis of microstructure in the welding zone of 9Cr-1Mo-V-Nb heat-resisting steel
}

\author{
LI YAJIANG*, WANG JUAN, ZHOU BING and FENG TAO \\ Key Lab of Liquid Structure and Heredity of Materials, Ministry of Education, School of Materials Science and \\ Engineering, Shandong University, Jinan 250061, People's Republic of China
}

MS received 3 December 2001

\begin{abstract}
Under the condition of tungsten inert gas shielded welding (TIG) + shielded metal arc welding (SMAW) technology, the microstructure in the welding zone of $9 \mathrm{Cr}-1 \mathrm{Mo}-\mathrm{V}-\mathrm{Nb}$ (P91) heat-resisting steel is studied by means of X-ray diffractometry (XRD) and transmission electron microscopy (TEM). The test results indicate that when the weld heat input $(E)$ of TIG is $8.5 \sim 11.7 \mathrm{~kJ} / \mathrm{cm}$ and the weld heat input of SMAW is $13.3 \sim 21.0 \mathrm{~kJ} / \mathrm{cm}$, the microstructure in the weld metal is composed of austenite and a little amount of $\delta$ ferrite. The substructure of austenite is crypto-crystal martensite, which included angle. There are some spot precipitates in the martensite base. TEM analysis indicates that the fine structure in the heat-affected zone is lath martensite. There are some carbides (lattice constant, $1.064 \mathrm{~nm}$ ) at the boundary of grain as well as inside the grain, most of which are $\mathrm{Cr}_{23} \mathrm{C}_{6}$ and a little amount of $(\mathrm{Fe}, \mathrm{Me})_{23} \mathrm{C}_{6}$.
\end{abstract}

Keywords. Heat-resisting steel; welding; fine structure.

\section{Introduction}

With the development of electric power industry, particularly the application of the heat-resisting steel in the thermal power system of high parameter and supercritical pressure, the welding quality of the heat-resisting steel is paid attention by many researchers (Tongfen 1995; Yunqing and Boli 1995; Dazhan et al 1998). Several components of the heating power equipment in the power station worked under conditions of high temperature $\left(450 \sim 700^{\circ} \mathrm{C}\right)$, high pressure $(10 \sim 22 \mathrm{MPa})$ and some corrosion media for a long time. Certain parts were required to bear larger restrain stress and vibration load (Brozda and Zeman 1995, 1996). Hence, main components of electric power equipment are made using a particular heat-resisting steel and using strict welding technology. Only under this strict condition, the welding zone can obtain good microstructure performance, and excellent chemical stability and enough strength and toughness under high temperature (Naoi et al 1997; Isaki et al 1988; Xin et al 2000).

In this paper, the microstructure performance in the welding zone of $9 \mathrm{Cr}-1 \mathrm{Mo}-\mathrm{V}-\mathrm{Nb}$ (P91) heat-resisting steel, which has highest $\mathrm{Cr}$ content in the heat-resisting $\mathrm{Cr}-\mathrm{Mo}$ steel system, are researched by means of X-ray diffractometry (XRD) and transition electron microscopy (TEM). Fine structures in the weld metal and the heataffected zone are analysed. This research provides essential

\footnotetext{
*Author for correspondence
}

experimental and theoretical base to optimize welding technology and determine optimum technology parameters.

\section{Experimental}

9Cr-1Mo-V-Nb (P91) heat-resisting steel used in this test was a steel pipe of $\Phi 234 \times 26 \mathrm{~mm}$. Heat treatment condition consisted of normalizing $1040 \sim 1080^{\circ} \mathrm{C}$ and tempering $730 \sim 780^{\circ} \mathrm{C}$ for about $60 \mathrm{~min}$. Chemical composition and mechanical properties of P91 steel are shown in table 1.

P91 steel pipe was welded by welding technology of TIG + SMAW, root run using TIG and weld face using SMAW. The butt joint was prepared into V-type groove and the gap between pipes was $3 \sim 4 \mathrm{~mm}$. Filler materials used in the test were Thyssen Tht MTS 3 wire and Thyssen Chromo 9V electrode produced by Germany Thyssen Company. Chemical compositions of wire and elctrode are shown in table 2. Welding parameters used in the test are shown in table 3. Pre-heat temperature of P91 heat-resisting steel was about $200^{\circ} \mathrm{C}$. Argon gas was filled into steel pipe $4 \sim 5 \mathrm{~min}$ in advance before welding to ensure the reversed side forming of the weld metal. Flow of the shielding gas was $8 \sim 10 \mathrm{~L} / \mathrm{min}$.

Some specimens were cut at the place of P91 steel welding joint and then made into metallographic samples. Diffraction analysis was conducted on P91 steel and weld samples to determine phase constitution in the welding zone by means of D/max-rc X-ray diffractometry (XRD). Some thin slices of about $0.5 \mathrm{~mm}$ were cut from P91 steel 
welding sample. By selecting the weld metal, heataffected zone and base metal, different zones were prepared into small circular slices of diameter about $2 \sim 3 \mathrm{~mm}$. These were ground into thickness of about $0.1 \mathrm{~mm}$ and were made into thin foils that are less than $50 \mu \mathrm{m}$ thickness using ion bombarding technology. These film samples were observed under TEM and select electron diffraction analysis was conducted.

\section{Results and analysis}

\subsection{XRD analysis}

In order to determine the phase constitution in the weld metal, the welding sample of P91 heat-resisting steel is analysed by means of D/max-rc-type X-ray diffractometry, using a copper target. The working voltage was $40 \mathrm{kV}$ and the working current was $150 \mathrm{~mA}$. The experimental results are shown in figure 1 . The inter planar spaces ( $d$ values) corresponding to the diffraction peaks in the diagram have been computed. These computed results have been compared with the inter planar spaces ( $d$ values) of $\alpha$-Fe phase and $\mathrm{Fe}-\mathrm{Cr}$ which have been published by the Joint Committee on Power Diffraction Standards (JCPDS), see table 4.
The corresponding phase near every diffraction peak in the diffraction diagram is marked. We can see from table 4 that the phase constitution of the base metal and weld metal for P91 steel consists of $\alpha-\mathrm{Fe}$ and $\mathrm{Fe}-\mathrm{Cr}$ phases. The crystal-space values of the base metal are close to that of the weld metal. This is because the composition of the weld metal is close to that of the P91 base metal. In contrast of relative strength ratio, $I / I_{1}$ of diffraction peak, the coincidence of $\mathrm{Fe}-\mathrm{Cr}$ phase is better than $\alpha-F e$ phase. Actually, every strength diffraction peak on the X-ray diffraction diagram is commonly formed of $\alpha$-Fe and $\mathrm{Fe}-\mathrm{Cr}$ phases. $\alpha$-Fe phase here expresses supersaturation solid solution (martensite) and ferrite. $\mathrm{Fe}-\mathrm{Cr}$ phase is the solid solution formed $\mathrm{Cr}$ element in the iron base.

\subsection{TEM observation}

To clarify further the morphology of the weld metal and the heat-affected zone of $9 \mathrm{Cr}-1 \mathrm{Mo}-\mathrm{V}-\mathrm{Nb}$ (P91) heatresisting steel, thin slices in the weld metal and HAZ were cut with line cutting machine and thin film samples were prepared. Then the fine structure in the weld metal and HAZ was examined by electron microscope (SEM, TEM) and select electron diffraction technique.

Table 1. Chemical composition and mechanical properties of $9 \mathrm{Cr}-1 \mathrm{Mo}-\mathrm{V}-\mathrm{Nb}$ heat-resisting steel.

\begin{tabular}{|c|c|c|c|c|c|c|c|c|c|}
\hline \multirow[b]{2}{*}{ Element } & \multicolumn{9}{|c|}{ Chemical composition (\%) } \\
\hline & $\mathrm{C}$ & $\mathrm{Mn}$ & $\mathrm{P}$ & S & $\mathrm{Si}$ & $\mathrm{Cr}$ & Mo & $\mathrm{V}$ & $\mathrm{Ni}$ \\
\hline \multirow[t]{3}{*}{$\begin{array}{l}\text { ASTM } \\
\text { standard }\end{array}$} & $\begin{array}{c}0 \cdot 11 \\
0 \cdot 08 \sim 0 \cdot 12\end{array}$ & $\begin{array}{c}0 \cdot 46 \\
0 \cdot 30 \sim 0 \cdot 60\end{array}$ & $\begin{aligned} & 0.015 \\
\leq & 0.015\end{aligned}$ & $\begin{array}{l}0.0038 \\
\leq 0.010\end{array}$ & $\begin{array}{c}0 \cdot 31 \\
0 \cdot 20 \sim 0 \cdot 50\end{array}$ & $\begin{array}{c}9 \cdot 46 \\
8 \cdot 00 \sim 9 \cdot 50\end{array}$ & $\begin{array}{c}0 \cdot 88 \\
0.85 \sim 1 \cdot 05\end{array}$ & $\begin{array}{c}0 \cdot 20 \\
0 \cdot 18 \sim 0 \cdot 25\end{array}$ & $\begin{array}{c}0.09 \\
\leq 0.40\end{array}$ \\
\hline & \multicolumn{9}{|c|}{ Mechanical properties } \\
\hline & & $\begin{array}{c}\text { Yield strength } \\
\sigma_{0.2}(\mathrm{MPa})\end{array}$ & \multicolumn{2}{|c|}{$\begin{array}{l}\text { Tensile strength } \\
\sigma_{\mathrm{b}}(\mathrm{Mpa})\end{array}$} & \multicolumn{2}{|c|}{$\begin{array}{c}\text { Elongation } \\
\delta_{5}(\%)\end{array}$} & $\begin{array}{l}\text { Hardness } \\
\text { (HB) }\end{array}$ & \multicolumn{2}{|c|}{$\begin{array}{l}\text { Impact work } \\
(\mathrm{Akv} / \mathrm{J})\end{array}$} \\
\hline ASTM A335 & & $\geq 415$ & \multicolumn{2}{|c|}{$\geq 585$} & \multicolumn{2}{|c|}{$\geq 20$} & $\leq 250$ & \multicolumn{2}{|c|}{$\geq 42$} \\
\hline
\end{tabular}

Table 2. Chemical composition (\%) of wire and electrode used in the test.

\begin{tabular}{lccccccccc}
\hline Welding materials & $\mathrm{C}$ & $\mathrm{Si}$ & $\mathrm{Mn}$ & $\mathrm{Cr}$ & $\mathrm{Mo}$ & $\mathrm{Ni}$ & $\mathrm{Nb}$ & $\mathrm{V}$ & $\mathrm{N}$ \\
\hline Thyssen Tht MTS 3 wire & $0 \cdot 10$ & 0.30 & 0.50 & $9 \cdot 0$ & 1.0 & 0.70 & 0.06 & 0.2 & - \\
Thyssen Chromo 9V electrode & 0.09 & 0.22 & 0.65 & $9 \cdot 0$ & $1 \cdot 1$ & $0 \cdot 80$ & 0.05 & 0.2 & 0.04 \\
\hline
\end{tabular}

Table 3. Welding technology parameters of $9 \mathrm{Cr}-1 \mathrm{Mo}-\mathrm{V}-\mathrm{Nb}$ steel used in the test.

\begin{tabular}{lclcccr}
\hline Layer & Method & Welding materials & $\begin{array}{c}\text { Welding current } \\
(\AA)\end{array}$ & $\begin{array}{c}\text { Welding voltage } \\
(\mathrm{V})\end{array}$ & $\begin{array}{c}\text { Welding speed } \\
\left(\mathrm{cm} \cdot \mathrm{s}^{-1}\right)\end{array}$ & $\begin{array}{c}\text { Weld heat input } \\
\left(\mathrm{kJ} \cdot \mathrm{cm}^{-1}\right)\end{array}$ \\
\hline 1 & TIG & Tht MTS 3 $(\Phi 2 \cdot 4)$ & $85 \sim 100$ & $10 \sim 14$ & $0 \cdot 10 \sim 0 \cdot 12$ & $8 \cdot 5 \sim 11 \cdot 7$ \\
2 & SMAW & Chromo 9V $(\Phi 2 \cdot 5)$ & $80 \sim 95$ & $20 \sim 24$ & $0 \cdot 12 \sim 0 \cdot 15$ & $13 \cdot 3 \sim 15 \cdot 2$ \\
$3-8$ & SMAW & Chromo 9V $(\Phi 3 \cdot 2)$ & $110 \sim 140$ & $20 \sim 24$ & $0 \cdot 12 \sim 0 \cdot 16$ & $18 \cdot 3 \sim 21 \cdot 0$ \\
\hline
\end{tabular}


Microstructure in the weld metal of $9 \mathrm{Cr}-1 \mathrm{Mo}-\mathrm{V}-\mathrm{Nb}$ (P91) steel is austenite and a small amount of $\delta$ ferrite. The substructure in austenite is lath martensite that has a certain angle. SEM microstructure of the weld metal is shown in figure 2. TEM morphology in the weld metal,

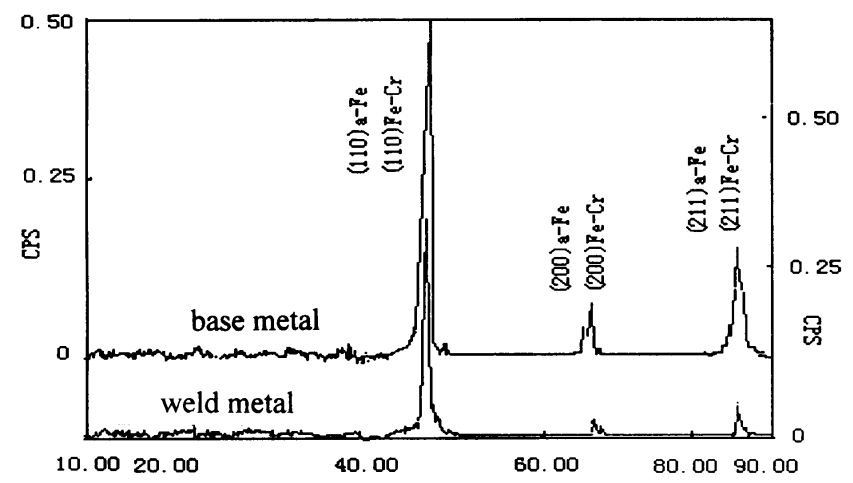

Figure 1. X-ray diffraction diagram from the base metal and weld metal of P91 steel. electron diffraction pattern and schematic index diagram, taken from [111] direction, are shown in figures 3a,b,c. The substructure of the weld metal is mainly lath martensite, in which dislocation density is higher. There are a lot of dislocation nets in martensite sub-grains and a small amount remains austenite in the boundary of lath martensite. There is a certain orientation relation between lath martensite and austenite according to diffraction pattern and schematic index diagram, viz. [111] crystal surface of lath martensite that has body-centred cubic structure is parallel to [100] crystal surface of the remaining austenite that has face-centred cubic structure.

Lath martensite (ML) morphology, local carbide precipitate and electron diffraction pattern in the heataffected zone of $9 \mathrm{Cr}-1 \mathrm{Mo}-\mathrm{V}-\mathrm{Nb}$ steel is shown in figure 4. Fine structure in the HAZ is lath martensite and there is a small amount of carbide precipitate at the local zone. Under TEM, carbide distributed in precipitating state can be clearly observed in the sub-structure of the HAZ. This $\mathrm{M}_{23} \mathrm{C}_{6}$ carbide of face-centred cubic structure (lattice constant, 1.064 nm) can be observed by electron
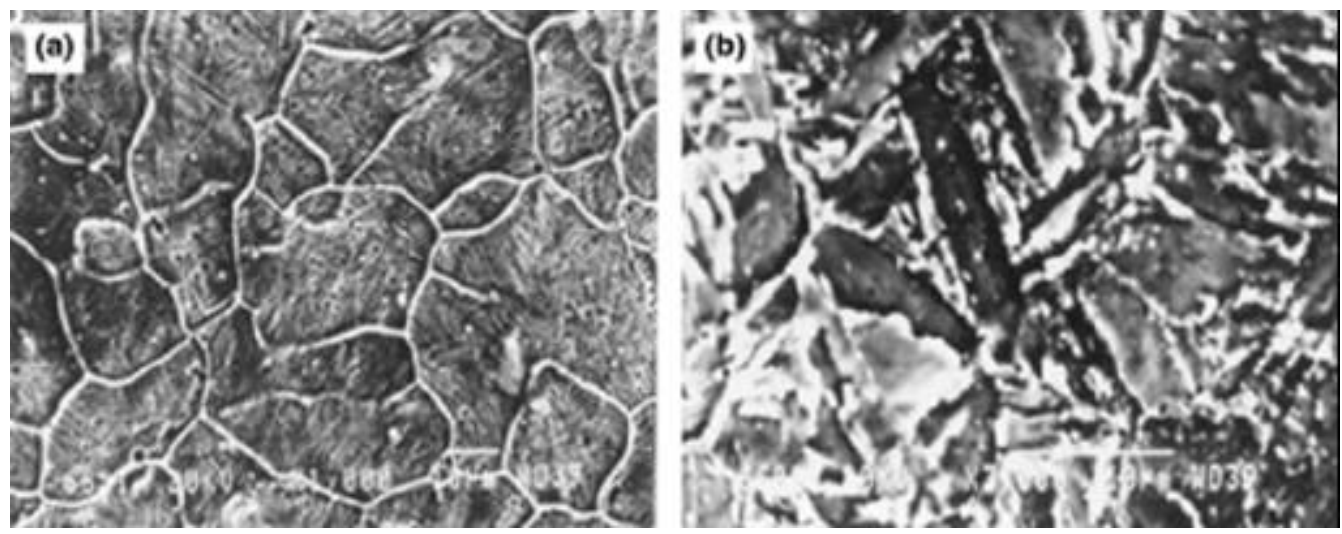

Figure 2. Microstructure in the weld metal and the heat-affected zone of $9 \mathrm{Cr}-1 \mathrm{Mo}-\mathrm{V}-\mathrm{Nb}$ steel (SEM): (a) weld metal $(\times 1000)$ and $(\mathbf{b})$ heat-affected zone $(\times 3000)$.

Table 4. The contrast of $\mathrm{X}$-ray diffraction value for $9 \mathrm{Cr}-1 \mathrm{Mo}-\mathrm{V}-\mathrm{Nb}$ base metal and weld metal.

\begin{tabular}{|c|c|c|c|c|c|c|c|c|}
\hline \multirow[b]{2}{*}{ Sample } & \multicolumn{2}{|c|}{$\begin{array}{l}\text { Measured values } \\
(\mathrm{d} / \mathrm{nm})\end{array}$} & \multicolumn{3}{|c|}{$\begin{array}{l}\text { Data card from JCPDS } \\
\text { No. } 6-669(\alpha-\mathrm{Fe})\end{array}$} & \multicolumn{3}{|c|}{$\begin{array}{l}\text { Data card from JCPDS } \\
\text { No. 34-396 (Fe-Cr) }\end{array}$} \\
\hline & $(\mathrm{d} / \mathrm{nm})$ & $\left(I / I_{1}\right)$ & $(\mathrm{d} / \mathrm{nm})$ & $\left(I / I_{1}\right)$ & $h k l$ & $(\mathrm{~d} / \mathrm{nm})$ & $\left(I / I_{1}\right)$ & $h k l$ \\
\hline \multirow[t]{5}{*}{ Base metal } & $0 \cdot 2033$ & 100 & $0 \cdot 2027$ & 100 & 110 & $0 \cdot 2035$ & 100 & 110 \\
\hline & $0 \cdot 1978$ & 2 & - & - & - & - & - & - \\
\hline & $0 \cdot 1444$ & 7 & - & - & - & - & - & - \\
\hline & $0 \cdot 1438$ & 13 & 0.1433 & 20 & 200 & 0.1438 & 20 & 200 \\
\hline & $0 \cdot 1174$ & 20 & $0 \cdot 1170$ & 30 & 211 & $0 \cdot 1174$ & 50 & 211 \\
\hline \multirow[t]{5}{*}{ Weld metal } & $0 \cdot 2033$ & 99 & $0 \cdot 2027$ & 100 & 110 & $0 \cdot 2035$ & 100 & 110 \\
\hline & $0 \cdot 1439$ & 16 & $0 \cdot 1433$ & 20 & 200 & $0 \cdot 1438$ & 20 & 200 \\
\hline & $0 \cdot 1430$ & 3 & - & - & - & - & - & - \\
\hline & $0 \cdot 1174$ & 24 & $0 \cdot 1170$ & 30 & 211 & $0 \cdot 1174$ & 50 & 211 \\
\hline & $0 \cdot 1165$ & 2 & - & - & - & - & - & - \\
\hline
\end{tabular}


diffraction analysis. EPMA analysis indicates that $\mathrm{M}_{23} \mathrm{C}_{6}$ carbide contains some alloy elements such as $\mathrm{Cr}, \mathrm{Fe}, \mathrm{Mo}$ etc. According to TEM analysis, this carbide is mainly $\mathrm{Cr}_{23} \mathrm{C}_{6}$ and also includes a small amount of $(\mathrm{Fe}, \mathrm{Me})_{23} \mathrm{C}_{6}$. The analysis result of electron diffraction pattern of typical carbide $\mathrm{Cr}_{23} \mathrm{C}_{6}$ in the HAZ of P91 steel is shown in table 5.

Under TEM condition, parallel twin structures in local areas of lath martensite sub-structure in the HAZ of $9 \mathrm{Cr}-1 \mathrm{Mo}-\mathrm{V}-\mathrm{Nb}(\mathrm{P} 21)$ steel can be observed which is confirmed through electron diffraction analysis. The twin martensite has high hardness and brittleness. Twin martensite produced in welding of heat-resisting steels should be avoided as far as possible. There is twin martensite in the HAZ that has lower carbon content mainly because P91 steel pipe has larger thickness, which makes HAZ cooling quick. Twin structure in lath microstructure of $9 \mathrm{Cr}-1 \mathrm{Mo}-\mathrm{V}-\mathrm{Nb}$ steel is different from that of high carbon steel. Twin structure in the HAZ of P91 steel only appears in some local area in lath microstructure and the quantity is very small. The other area has many dislocation lines that have high density. Twin structure in high carbon martensite densely arranges and spreads all over martensite. Hence, a small amount of twin substructure that occasionally appeared in a large amount of dislocation martensite has little effect on the microstructure performance in the $\mathrm{HAZ}$ of $9 \mathrm{Cr}-1 \mathrm{Mo}-\mathrm{V}-$ $\mathrm{Nb}$ steel.
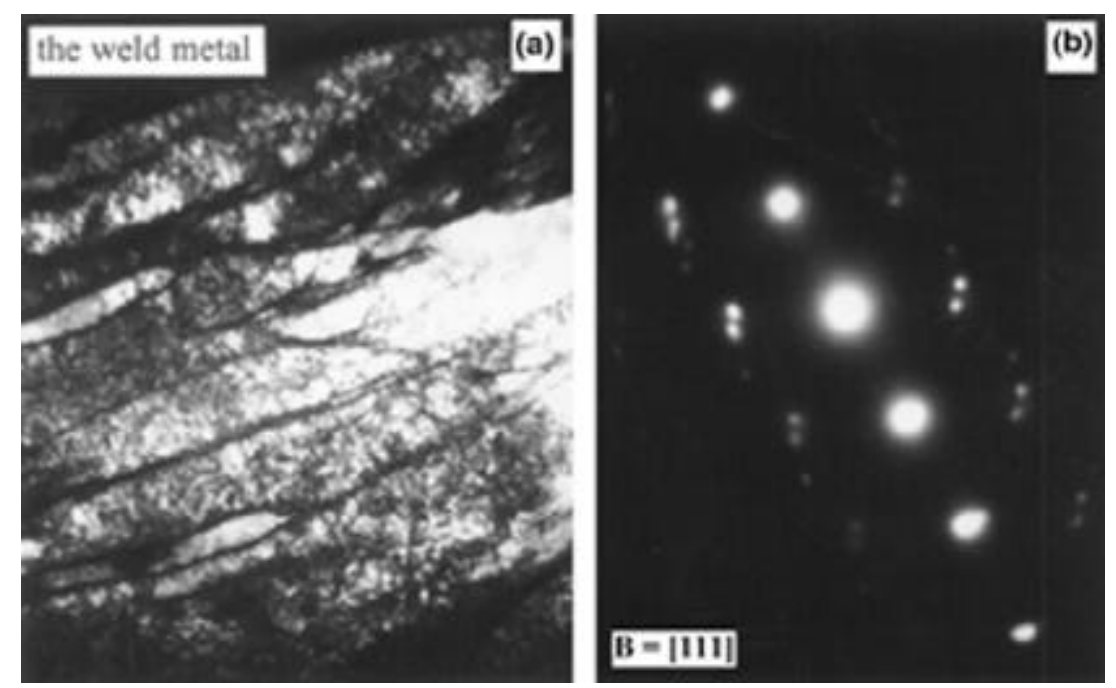

(c)

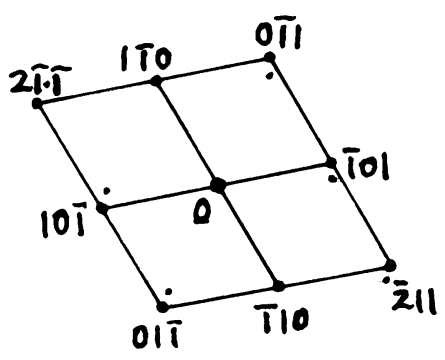

$B=[111]$

Figure 3. Structure characteristics in the weld metal of $9 \mathrm{Cr}-1 \mathrm{Mo}-\mathrm{V}-\mathrm{Nb}$ steel $(\mathrm{TEM})$ : (a) TEM morphology $(\times 25000)$, (b) electron diffraction pattern and (c) schematic diagram.
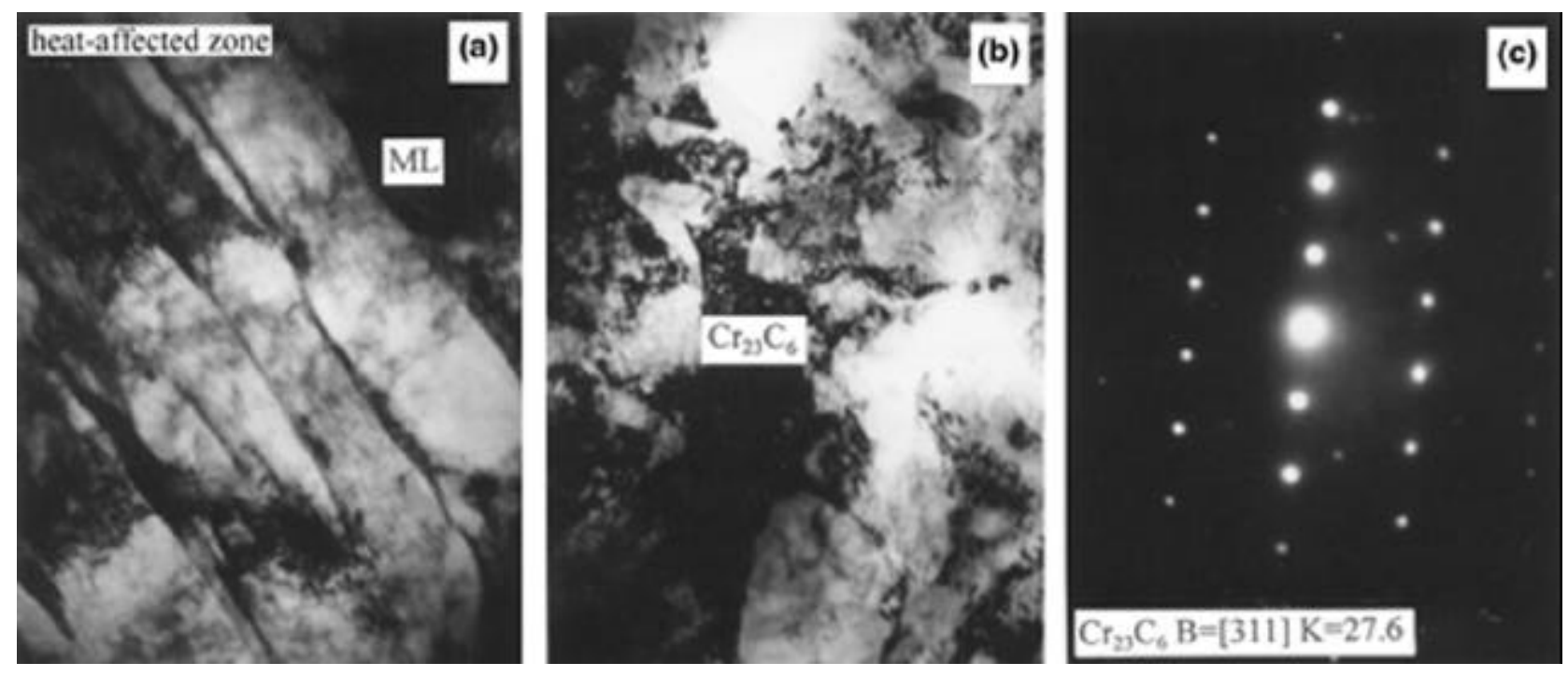

Figure 4. Structure characteristics in the heat-affected zone of $9 \mathrm{Cr}-1 \mathrm{Mo}-\mathrm{V}-\mathrm{Nb}$ (P91) steel (TEM): (a) ML morphology $(\times 40000),(b)$ local carbide precipitate $(\times 50000)$ and $(\mathbf{c})$ electron diffraction pattern. 
Table 5. Electron diffraction results of typical carbide in the $\mathrm{HAZ}$ of $9 \mathrm{Cr}-1 \mathrm{Mo}-\mathrm{V}-\mathrm{Nb}$ steel.

\begin{tabular}{cccccc}
\hline Carbide & Spots & $R_{\mathrm{j}} / \mathrm{mm}$ & $h k l$ & $\mathrm{~d} / \mathrm{mm}$ & $\begin{array}{c}\mathrm{d} / \mathrm{mm} \\
\text { (from ASTM } \\
\text { card) }\end{array}$ \\
\hline & $\mathrm{A}$ & $7 \cdot 8$ & 022 & $3 \cdot 54$ & 3.58 \\
$\mathrm{Cr}_{23} \mathrm{C}_{6}$ & $\mathrm{~B}$ & $13 \cdot 4$ & 224 & $2 \cdot 06$ & $2 \cdot 07$ \\
& $\mathrm{C}$ & $13 \cdot 4$ & 242 & $2 \cdot 06$ & $2 \cdot 07$ \\
\hline
\end{tabular}

Note: Camera constant, $K=27 \cdot 6$.

\section{Conclusions}

(I) $9 \mathrm{Cr}-1 \mathrm{Mo}-\mathrm{V}-\mathrm{Nb}$ (P91) heat-resisting steel pipe of $\Phi 234 \times 26 \mathrm{~mm}$ can be welded using TIG + SMAW technology. The microstructure performance of the weld metal and heat-affected zone can be ensured when TIG heat input is $E=8.5 \sim 11.7 \mathrm{~kJ} / \mathrm{cm}$ and SMAW heat input, $E=13 \cdot 3 \sim 21 \cdot 0 \mathrm{~kJ} / \mathrm{cm}$.

(II) Microstructure of the weld metal for P91 steel consists of austenite and a small amount of ferrite. Substructure inside austenite is lath martensite hidden from view that has certain angle. There are some spot precipitates in the martensite base. X-ray diffraction indicates that the P91 base metal and weld metal consists of $\alpha$-Fe and $\mathrm{Fe}-\mathrm{Cr}$ phases, respectively.

(III) TEM analysis indicates that fine structure in the $\mathrm{HAZ}$ is lath martensite and a small amount of $\mathrm{M}_{23} \mathrm{C}_{6}$ carbide (lattice constant, $1.064 \mathrm{~nm}$ ) is precipitately distri- buted on the boundary and inside lath martensite. The carbide mainly is $\mathrm{Cr}_{23} \mathrm{C}_{6}$ but also contains a small amount of $(\mathrm{Fe}, \mathrm{Me})_{23} \mathrm{C}_{6}$.

\section{Acknowledgement}

The work was supported by the Visiting Scholar Foundation of the National Key Laboratory of Advanced Welding Production Technology, Harbin Institute of Technology, P.R. China. The authors express their heartfelt thanks.

\section{References}

Brozda J and Zeman M 1995 Weld. Res. Abroad 1233 Brozda J and Zeman M 1996 Weld. Res. Abroad 1058 Dazhan Guo, Fenlan Li and Ruihua Zhu 1998 J. Xi'an Univ. 32 66

Isaki H, Kabayashi O and Yoichikume R 1988 Trans. Jpn Weld. Soc. 1963

Naoi H, Ohgami M, Liu X and Fujita T 1997 Metall. \& Mater. Trans. 281195

Tongfen Wang 1995 Welding 18 (in Chinese)

Xin Long, Yonggang Xu and Guangjun Cai 2000 Trans. China Weld. Inst. 2153

Yunqing Huang and Boli Chen 1995 China Weld. 431

Zengda Zou, Yajiang Li and Shike Yin 2000 Welding and engineering application of low alloy quench-and-tempering high strength steels (Beijing: Chemical Industry Publishing House) 